\title{
The importance of financial recession for mental health among students: short- and long-term analyses from an ecosocial perspective
}

\author{
Ann Hammarström, ${ }^{1,2}$ Pekka Virtanen ${ }^{3}$ \\ ${ }^{1}$ Institute of Environmental Medicine, Karolinska Institutet, Stockholm, Sweden; ${ }^{2}$ The Stress Research \\ Institute, Stockholm University, Stockholm, Sweden; ${ }^{3}$ Faculty of Social Sciences, Tampere University, \\ Tampere, Finland
}

Significance for public health

Although those who study at age 21 may be considered as a relatively healthy and advantaged population group in the long run, our results provide evidence for the significance of recession for mental health, not only among those suffering from concrete job loss but across all population groups. Students' mental health should be given high priority during times of financial crisis. Mental health services for students should receive increased resources during times of recession. Even if young people may be reluctant to study after school during a financial crisis, it seems to be beneficial for their mental health in a long-term perspective. So, for them poorer mental health does not seem to be dangerous in the long run. Students surveys should pay special attention to understanding the relation between macroeconomic conditions and individual mental health symptoms.

\footnotetext{
Abstract

Background and aim: Referring to the ecosocial theory and utilising the 'natural experiment' setting provided by the global recession at the beginning of 1990 s, the aim of our study was to analyse the short- and long-term associations between trade and mental health in young students followed until mid-adulthood.

Method: The study was based on two prospective cohort studies, the older and the younger Northern Swedish Cohort which both consisted of all pupils in a middle-sized industrial town in Northern Sweden. At age 21, the younger cohort entered the labour market during the deep recession of the early 1990s, while the older cohort entered the labour market during the boom of the 1980 s. Both cohorts were followed up with a high response rate in mid adulthood. For this study, all students were selected at age 21.

Results: At age 21, those who studied during recession had more depressive and functional somatic symptoms than those who studied during boom. The cohort differences did not remain over age: by the follow-up in early middle age the differences between the cohorts were non-significant, most notably due to decreased depressive symptoms in the younger cohort and increase of functional somatic symptoms in the older cohort.

Conclusions: The short-term mental health consequences of the business cycle seem to be more extensive than limited only to those who are unemployed, even though the possible long-term consequences seem to be more complex. Thus, the macrolevel had a great short-term impact on the individual level in relation to the microlevel setting of university/school. The chronosystem was also of major importance. Future research would benefit from taking the context into account.
}

\section{Introduction}

Research has for several decades analysed the negative health consequences of financial recession on an aggregate level. Harvey Brenner used aggregate time-series data to analyse countercyclical variations in mortality in US during the 1970 s. ${ }^{1-3}$ His conclusions about societal unemployment leading to increased population mortality have been criticised for serious flaws in the analy$\mathrm{ses}^{4}$ and researchers correcting these problems have failed to replicate his findings. ${ }^{5}$ Other aggregate-level studies indicate improved health and decreased mortality during recession, which may be explained by decreased traffic accidents, decreased alcohol consumption and more time for physical activities. ${ }^{6,7}$

However, while aggregate-level studies can be important for suggesting negative health consequences of societal structures, they do not analyse the individual level and therefore cannot be used to draw conclusions about individual health effects. A solution to this problem is - as proposed by the ecosocial theory ${ }^{8}$ as well as by the theory of ecology of human development ${ }^{9}-$ to utilise individual-level data to specify the target and the effects of the macro-level economy. An ecosocial perspective offers a way to simultaneously emphasise both the individual and the context and the relations between them. ${ }^{8}$ The importance of the context has been emphasised to be of particular importance for human development, and mental health can be seen as an essential track of such development. Urie Bronfenbrenner's ecological theory of human development is of special importance since the theory can be used to analyse how mental health develops from young age in close interplay with the larger social context on various levels such as the micro-, meso-, exo-, macro-, and chronolevel. ${ }^{9}$ As our focus in this paper is on the social context we prefer to use the concept ecosocial developed by Krieger. ${ }^{8}$

The individual level includes the developing human beings and their experiences of mental health symptoms. The microlevel consists of immediate settings around the individual, such as the family, the school, the peer group, the work place. The second level, the mesolevel, requires that we look beyond single settings to the interrelations between them. The exolevel represents social structures which the young person is not actively involved in but which are of major importance for development, such as the neighbourhood and the parental labour market. The macrolevel refers to overarching institutional patterns of society, such as the financial, economic, legal and social framework. Last, the chronolevel encompasses the temporal dimension and the gradual and discrete changes of the context that occur over time, as well as the individual life history. The various levels are conceived as a set of nested structures, each inside the next like a set of Russian dolls. According to Bronfenbrenner, ${ }^{9}$ research on the ecology of 
human development should preferably include experiments involving the ecological systems. The huge and unexpected financial crisis of the early 1990 s can be regarded as such an experiment on the macrolevel, which hit human beings differently depending on which developmental phase and which context they were in.

Since Brenner's early work there is increasing evidence that financial crises impact negatively on the mental health of the unemployed individual across countries and over time. Two reviews conclude that the financial crisis in 2008 had negative effects on mental health, although the conclusions about causal relations are hampered by the fact that most of the analysed studies had a cross-sectional and ecological design. ${ }^{10,11}$

Most research on unemployment has been performed without taking the financial context into account. In these studies, unemployment could be viewed as a setting on the microlevel. The available studies taking the macrolevel unemployment into account have focused on the effect of the financial crisis on unemployed individuals ${ }^{12,13}$ and show that the health effects of individual-level unemployment seem to be similar in boom and recession. ${ }^{12,14}$

A few of the earlier studies in the field have not only analysed the mental health effect of recession on the unemployed but also on other groups. An Icelandic cohort study analysed mental health of a nation-level cohort before and after the recession in 2008. The study found that the stress levels increased among women, especially those who were unemployed and those who studied after as compared to before the recession. ${ }^{15}$ A Spanish study has shown deteriorated mental health during the 2008 recession among both unemployed and short-term educated employed, ${ }^{13}$ while another study showed negative mental health effects during the same recession only among men independent of labour market position. ${ }^{16} \mathrm{~A}$ fourth study found complex relations in men when comparing cross-sectional studies several years before and after 2008.17 Methodological problems in these studies include lack of individual level data, long-term between studies before and after recession and thus difficulties in analysing possible effects of the recession.

In our own research from Sweden we have compared those who were 21 years of age in two extreme business cycles, and found more somatic and mental symptoms among those who work and study during recession compared to boom, especially among women. ${ }^{18}$

The reasons for students' poor health during recession are evident. In addition to being worried about finding a job, during a heavy recession the students may prefer to delay their graduation rather than becoming unemployed, which is also a stressful situation. Moreover, many of the new students may feel forced to study while they would rather work. But it is unclear whether these differential short-term effects of the 'exposure to education' remain over time.

In earlier research we have shown that from a life-course perspective there seems to be a 'scarring' effect of youth unemployment, meaning that youth unemployment seems to have long-lasting effects on mental health independent of later exposure and circumstances. ${ }^{19,20}$ A possible mechanism behind such 'scarring' could be that the youth is a sensitive period in which exposure to adverse life events such as unemployment has a profound impact on young people's self-esteem and cognitive maps. Moreover, the unemployment-related 'scarring' seems to be independent of the state of the macro economy - or unemployment rate - at the time of the exposure. ${ }^{12}$

So, an important research question is whether or not there are similar 'scarring' effects of studying during recession. Or, does the education pay in the long run so that the negative health effects of recession among students are transient or even become more posi- tive? Referring to the ecosocial theory and utilising the "natural experiment' setting provided by the global recession at the beginning of the 1990s, the response of the Swedish labour market policy to the crisis, and the data on the mental well-being of two student cohorts, the aim of our study was to analyse the short- and long-term associations between trade and mental health in the cohorts followed until mid-adulthood.

\section{Materials and Methods}

\section{Population}

The study was based on two prospective cohort studies, the older and the younger Northern Swedish Cohort (Table 1). ${ }^{12,21}$

The older cohort (Cohort65, most of them born in 1965) included all pupils who finished their compulsory school in 1981, and the younger cohort (Cohort73, most of them born in 1973) those who finished in 1989 in the same middle-sized industrial town of Northern Sweden.

The cohorts were investigated with similar questionnaires at age 21 (Cohort65 in 1986, Cohort73 in 1994) and in adulthood (Cohort65 at age 43, Cohort73 at age 39). The response rates at age 21 were $97.9 \%$ in Cohort65 and $90.0 \%$ in Cohort 73 and in adult age, respectively, 94.3\% $(\mathrm{n}=1001)$ and $85.6 \%(\mathrm{n}=686)$.

The sample for the present study (Cohort65, $n=144)$ and in 2012 (Cohort73, $\mathrm{n}=233$ ) was obtained by pooling those members of the two cohorts who were studying at age 21 either at university or at some other school, and who responded in the follow-up surveys in 2008 .

Ethical approval for the study has been given by the Regional Ethics Vetting Board in Umeå, Sweden.

\section{Setting}

At age 21 the cohort participants were facing the labour market in totally different trades (Figure 1). While Cohort65 entered the labour market in a pronounced boom (with youth unemployment levels less than 5 per cent) Cohort73 entered the labour market during the sudden and deep recession of the early 1990s (with youth unemployment rate of almost 25 per cent).

During the recession in the early 1990s, the Swedish government could not meet all needs for employment with an increased volume of active labour market measures. Another strategy to combat unemployment was a heavy increase in the number of places in educational programmes for students, after graduating from high school. The number of students aged 20-24 in Sweden increased from around 10 per cent in 1980 to 25 per cent during the 1990ies. A new law in 1993 gave the universities increased freedom to decide over their teaching. Thus, local regional needs such as high rate of youth unemployment could be and was also met by the universities with increased number of training sites in various educational programmes.

Table 1. Temporal scheme of the design of the two cohorts.

\begin{tabular}{lcc} 
& Cohort65 & Cohort73 \\
Year of birth & 1965 & 1973 \\
Year of baseline survey & 1986 & 1994 \\
\hline Year of follow-up survey & 2008 & 2012 \\
\hline
\end{tabular}




\section{Measures}

Our measures are described in relation to the levels which we use in Bronfenbrenner's model.

The individual level: Gender was measured as men and women. Two indicators of mental health were measured at baseline and at follow-up. Depressive symptom score (DSS) was based on six symptoms defined in DSM-5, ${ }^{22}$ i.e. sleeplessness, poor appetite, fatigue, concentration difficulties, feeling down or sad, and feeling downhearted about the future. Functional somatic symptoms (FSS) was a score of ten symptoms: headache or migraine; other stomach ache (than heartburn, gastritis or gastric ulcer); nausea; backache, hip pain or sciatica; general tiredness; breathlessness; dizziness; overstrain; sleeping problems; and palpitations (for details of the variable construction, see Hammarström et al.). ${ }^{23}$

Microlevel: Cohort participants' own education at age 21 was classified into 'university' and 'other' such as the two-year education to assistant nurse.

Exolevel: Social background was based on questionnaire information about parental occupation at age 16 (both cohorts). The occupations were coded on the basis of the social class classification of the Low Income Commission (Johansson 1970). The students with both parents in the working class were classified as having a 'working-class' background, those having one working-class parent were defined as having a 'mixed class', and those with no working-class parent were defined as 'middle-class' background.

Macrolevel: Macroeconomic context at age 21 was measured as a dichotomous variable (boom vs. recession) on the basis of membership (Cohort65 vs. Cohort73).

Chronolevel: This level is represented by the timespan between the follow-up of the two cohorts (from age 21 until age 39/43)

\section{Statistics}

Cross-sectional differences in DSS and FSS between Cohort65 and Cohort73 were assessed with univariate variance analysis. Changes of the symptoms from baseline to follow-up were studied with analysis of variance for repeated measures. Directions of the changes by cohort were plotted in figures with estimated marginal means on the $\mathrm{y}$-axis and time on the $\mathrm{x}$-axis, and statistical significance of the differences between the cohorts (i.e. divergence in the direction of the lines) was assessed on basis of the P-values for time*cohort interactions, controlling for gender, type of education and social background. The analyses were made with SPSS version 25.

\section{Results}

The background characteristics of the two cohorts are described in Table 2. The proportion of women was somewhat higher in Cohort73. Almost half of Cohort65 and one third of Cohort73 had a middle-class background, and about one of five in both cohorts a working-class background. The proportion of university students was higher in Cohort73. About one of four participants of both cohorts were cohabiting, very few were married, and virtually nobody of those studying at age 21 had children

Table 3 shows crude means of DSS. At baseline, the mean of Cohort73 was significantly higher than the mean of Cohort65 $(0.50$ vs 0.37 ). At follow-up the difference between the cohorts ( 0.43 vs. 0.38 ) was non-significant. The change from baseline to follow-up (decrease from 0.50 to 0.38 ) of Cohort 73 was significant, whereas the increase of Cohort65 did not reach statistical significance. In corresponding analyses on FSS (Table 4) the cross-sectional differ-
Table 2. Descriptive statistics at the baseline (age 21) of the study sample by cohort (Cohort65 studying at baseline in 1986; Cohort73 studying at baseline in 1994).

\section{Cohort65, \% n=156 Cohort73, \% n=233}

\begin{tabular}{lcc} 
Gender & & \\
Men & 47 & 41 \\
Women & 53 & 59 \\
Social background & & \\
Middle class & 43 & 33 \\
Mixed class & 37 & 45 \\
Working class & 20 & 23 \\
\hline Type of education & & \\
University & 59 & 70 \\
Other & 41 & 30 \\
Cohabiting & & \\
Yes & 26 & 24. \\
No & 80 & 76 \\
\hline Children & & \\
Yes & 3 & 0 \\
No & 97 & 100 \\
\hline
\end{tabular}

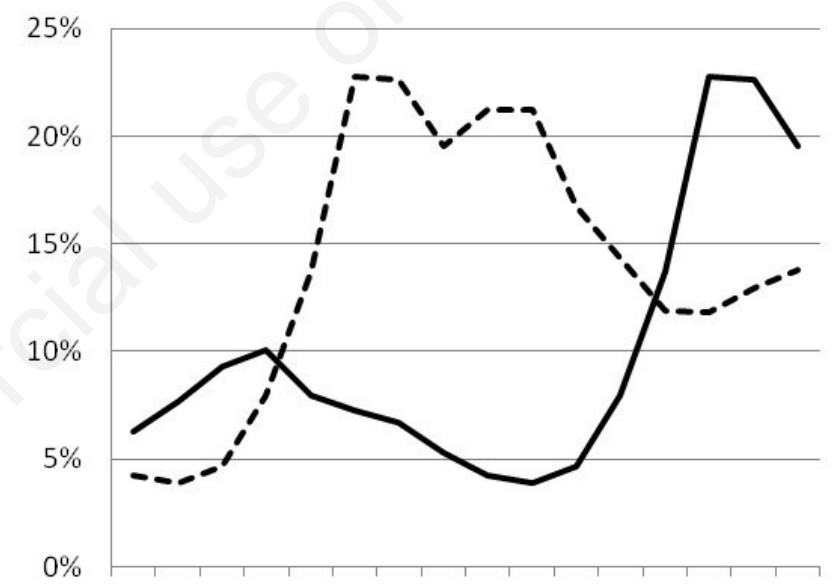

15161718192021222324252627282930

Figure 1. Levels of youth unemployment in Sweden (annual mean values for Sweden from OECD StatExtracts) on the $x$-axis Related to various ages (15-30) (on the y-axis) in Cohort65 (unbroken line) compared to Cohort73 (dotted line).

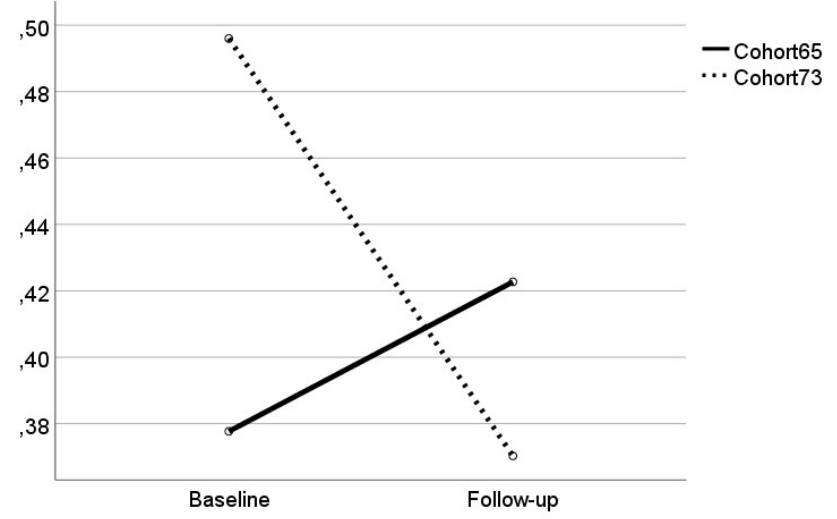

Figure 2. Change of depressive symptom score from baseline (age 21) to follow-up (age 39/43) by cohort. Estimated marginal means adjusted for gender, study level and social background. 
ences were likewise significant at baseline and non-significant at follow-up and, in contrast to DSS, the score of Cohort73 did not decrease and the score of Cohort65 increased significantly.

Figure 2 illustrates the differences between the cohorts in the changes of depressive symptoms from baseline to follow-up. Looking at DSS, the line of Cohort73 slopes steeply downwards, whereas the line of Cohort65 is directed slightly upwards. The cohort*time interaction is highly significant $(\mathrm{P}<0.001)$.

A corresponding analysis on FSS (Figure 3 ) shows that the means tend to increase with age in both cohorts, but in Cohort65 the upward slope is steeper than in Cohort73, and the cohort*time interaction turns out to be highly significant (P-values 0.005).

The unadjusted figures were very similar. Overall, women reported more symptoms than men also in our data. However, the changes in symptoms did not depend on gender (P-values of cohort*time*gender interactions 0.393 for DSS and 0.521 for FSS). Thus, there was no reason to stratify the analysis by gender.

\section{Discussion}

\section{On the findings}

Our baseline results showed that those 21-year-olds who studied during a recession (Cohort73) had more depressive and functional somatic symptoms than those who studied during a boom (Cohort65). The cohort differences did not remain over age: by the follow-up in early middle age the differences between the cohorts were non-significant, most notably due to decreased DSS in Cohort73 and increased FSS in Cohort65.

We have used two different indicators of symptoms of mental health. Both describe very high levels of symptoms at baseline in Cohort73. At follow-up, the increased score of FSS in Cohort65 can be regarded as more 'normal', due to the age-related increase in some of the symptoms within the measure (such as back pain and tiredness), than the unchanged score in Cohort73. As regards DSS, the steep decrease in depressiveness in Cohort73 over life in combination with the tendency to an increase in depressiveness in Cohort65 is surprising and cannot be fully explained in this study. A possible explanation for the different directions could be the higher non-response in Cohort73, since it is known that nonresponders often have worse mental health than responders. ${ }^{24}$ However, the response rate is still high in that cohort, especially by international standards.

Although early adulthood can be considered as a period of particular sensitivity for obtaining long-term damage to mental health, macroeconomic environment later during the life course may also be reflected in mental health. Considering the present study, the older cohort was exposed to recession from age 28 to age 32 , when they already had entered the labour market. It is possible that the associated unstable employment and open unemployment have contributed to the relatively poor development of their mental health during the follow-up. Analogously, we may conclude that mental health of the younger cohort had improved by the follow-up in spite of potential worsening due to the financial crisis that began in 2008. We lack data from Cohort73 to compare the possible health effects of being hit by the trade at that age. In any case, we can speculate that one may be more protected by microlevel settings (having partner, children) at age 28 as compared to at age 21 .

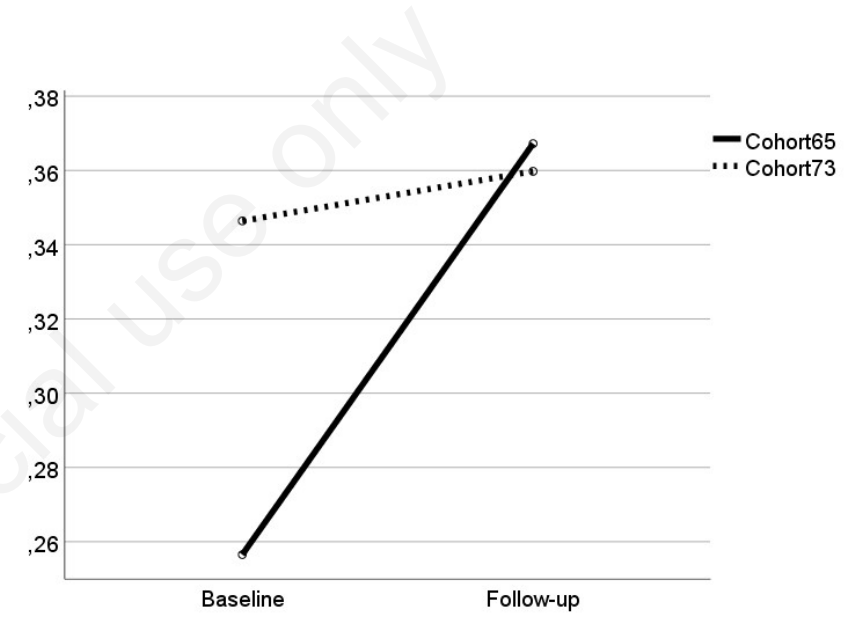

Figure 3. Change of functional somatic symptom score from baseline (age 21) to follow-up (age 39/43) by cohort. Estimated marginal means adjusted for gender, study level and social background.

Table 3. Depressive symptom scores (estimated marginal means and $95 \%$ confidence intervals) at the baseline and at the follow-up by cohort.

\title{
Baseline
}

\section{Cohort65}

$0.37(0.33-0.42)$

Cohort73

$0.50(0.45-0.54)$

$\mathrm{P}<0.001$ Follow-up

\author{
$0.42(0.37-0.48)$
}

$0.38(0.32-0.42)$

Between-cohort difference*

*Univariate analysis of variance, adjusted for gender, social background and study level; analysis of variance for repeated measures.

$\mathrm{P}=0.223$

Table 4. Functional somatic symptom scores (estimated marginal means and $95 \%$ confidence intervals) at baseline and at follow-up by cohort.

\begin{tabular}{lccc} 
& Baseline & Follow-up & Within-cohort change \\
Cohort 65 & $0.25(0.22-0.30)$ & $0.37(0.32-0.42)$ & $\mathrm{P}<0.001$ \\
Cohort 73 & $0.35(0.31-0.38)$ & $0.37(0.32-0.40)$ & $\mathrm{P}=0.441$ \\
\hline Between-cohort difference* & $\mathrm{P}=0.001$ & $\mathrm{P}=0.616$ & \\
\hline
\end{tabular}

*Univariate analysis of variance, adjusted for gender, social background and study level; analysis of variance for repeated measures. 
What about the macroeconomic situation at the time of the follow-up? Neither of the cohorts was investigated during a financial crisis at the time of the follow-up. The follow-up of Cohort65 was initiated in 2007 and mainly completed during spring 2008, before the major and sudden recession in September 2008. In addition, even though the levels of unemployment in Sweden were higher in Cohort65 at the time of investigation in adulthood compared to at age 21 , most of the cohort members were already established on the labour market and protected by buffering settings on the microlevel (such as the family, friends, associations) and therefore the societal unemployment was probably of less importance in adulthood.

In sum, our results suggest that the macroeconomic context impacts on the mental well-being of students in young age, but this impact is transient over life. Thus, the macrolevel had a great short-term impact on the individual level in relation to the microlevel setting of university/school. The chronosystem was also of major importance as the mental health patterns changed over the life course. In the other words: although studying during recession is associated with poor mental health, this is not visible as long-lasting 'mental health scars'

Our findings regarding the negative impact of recession on mental health among students are supported by research from Iceland. ${ }^{15}$ The Icelandic study found deteriorated mental health among women but not among men who studied. Our earlier publication on cross-sectional cohort comparison ${ }^{18}$ showed similar findings among women only.

Based on Bronfenbrenner's ecological theory of human development, these findings may be understood as contextualised, in which health status is related to microlevel settings (being a student), which in turn is nested within exolevel (parental background) and macrolevel structures (financial recession). Students during recession may be stressed due to the high levels of unemployment in society, fearing that their education will result in poor employment prospects. In addition, many of those who were students during the recession would have preferred to find employment instead of studying. Research from working life shows that being in a non-preferred employment is related to deteriorated well-being ${ }^{25}$ and it is reasonable to transfer a similar feeling of lack of control, known to be related to mental health symptoms ${ }^{26}$ to other labour market positions such as studying.

A study analysing the large variation across European countries in educational gradients in income and various measures of health found that cohorts that graduate from nine years of schooling at times of high unemployment rate in society have poorer health and health behaviour as well as lower income for many years after graduation as compared to those who graduate during low levels of unemployment. ${ }^{27}$ The 'scarring' effect of high levels of unemployment was most evident for younger cohorts ( $<40$ years of age which is about the age of our study) but contrary to our study the effect was not evident for those with 15 years of education. The reason for the different results could be that our study focused only on those who were students during different trades, while the other study analysed results for the whole cohort.

During life (defined as the chronosystem in Bronfenbrenner's ecological model), the mental health of those who were students in recession may have improved thanks to their 'forced' studies: the education could have started a positive chain of possibilities, leading to more qualified jobs with better salaries and improved work environment, compared to those who entered the labour market during a boom without studying.

Overall, our study provides an example of how to test the ecosocial model by utilising macrolevel and microlevel in relation to mental health symptoms among individuals in a longitudinal setting - and the difficulty in interpreting the findings.

\section{On the methods}

The main limitation of our study is the small size of the samples. However, we have two total investigations of a specific age group, which decreases the problems of power. The main strengths of our study are the high response rate over time in both cohorts and the fact that the cohorts have been proven to be comparable to the country as a whole with regard to socio-demographic and socio-economic factors as well as health status and health behaviour. $^{21}$

Our measures of mental health are based on what was available in Scandinavia in the early 1980s; single questions about various mental health symptoms. The measures have been validated against the golden standard of today in psychiatric research. As an overall assessment, the results showed that the composite measures (based on more than 30-year old single-item questions) are likely to have acceptable factorial invariance as well as internal consistency over time. ${ }^{23}$ On the other hand, there is no reference standard available with exactly same symptoms and reply scale, as the variables were particularly constructed for Northern Swedish Cohort Study in 1981, when no golden standard was available. ${ }^{23}$ With respect to FSS, the score included symptoms (e.g. musculoskeletal pain, breathlessness) that increase by age also due to the increasing prevalence of somatic diseases; this is why we conclude that Cohort65 represents 'natural' situation whereas in Cohort73 the finding is due to exceptionally high level at the baseline.

We chose to use unemployment rate as indicator of the context of our main interest, which was the macrolevel economy. More detailed analysis with alternative indicators used in economics, such as gross domestic product or volume of the international trade or level of public expenses, is out of the scope of this study. Generally, they fluctuate in line with the unemployment rate.

The question about causality needs to be discussed. Our comparison between two cohorts at age 21 do not permit causal conclusions. However, the two cohorts were selected in the same town and in exactly the same way, only eight years apart. The main difference between the cohorts at age 21 is the various trades they had been exposed to during the important period of entering the labour market. Thus, our findings suggest that the macro economy had an impact even though we cannot prove causal relations.

\section{Conclusions}

The short-term mental health effects of the business cycle seem to be more extensive than limited only to those who are unemployed, even though the possible long-term consequences seem to be more complex. Thus, the macrolevel seems to impact on the individual's mental health at young age in relation to the microlevel setting of university/school. The chronosystem was also of major importance as the development of mental health problems differed substantially between the cohorts. Future research would benefit from taking the context into account. 
Correspondence: Ann Hammarström, Institute of Environmental Medicine, Karolinska Institutet, Box 210, SE-171 77 Stockholm, Sweden.

E-mail: anne.hammarstrom@su.se

Key words: macroeconomics, students, mental health.

Acknowledgments: the authors would like to thank the participants of the study.

Contributions: $\mathrm{AH}$, data collecting, manuscript writing and references search; PV, analysing; manuscript reviewing.

Conflicts of interest: the authors declare no potential conflict of interests.

Funding: The work was supported by grants from The Swedish Research Council Formas (grant number 259-2012-37) and The Swedish Research Council for Health, Working Life and Welfare Forte (grant number 2011-0445).

Received for publication: 23 October 2018.

Revision received: 10 May 2019.

Accepted for publication: 23 May 2019.

${ }^{(C)}$ Copyright: the Author(s), 2019

Licensee PAGEPress, Italy

Journal of Public Health Research 2019;8:1504

doi:10.4081/jphr.2019.1504

This work is licensed under a Creative Commons Attribution NonCommercial 4.0 License (CC BY-NC 4.0).

\section{References}

1. Brenner MH. Economic change, alcohol consumption and heart disease mortality in nine industrialized countries. Soc Sci Med 1987;25:119-32.

2. Brenner MH. Relation of economic change to Swedish health and social well-being, 1950-1980. Soc Sci Med 1987;25:18395.

3. Brenner MH. Commentary: economic growth is the basis of mortality rate decline in the 20th century--experience of the United States 1901-2000. Int J Epidemiol 2005;34:1214-21.

4. Nurminen M. Linkage failures in ecological studies. World Health Stat Q 1995;48:78-84.

5. Wagstaff A. Time series analysis of the relationship between unemployment and mortality: a survey of econometric critiques and replications of Brenner's studies. Soc Sci Med 1985;21:985-96.

6. Gerdtham UG, Ruhm CJ. Deaths rise in good economic times: evidence from the OECD. Econ Hum Biol 2006;4:298-316.

7. Ruhm CJ. Commentary: mortality increases during economic upturns. Int J Epidemiol 2005;34:1206-11.

8. Krieger N. Theories for social epidemiology for the 21 st century. An ecosocial perspective. Int $\mathrm{J}$ Epidemiology 2001;30:668-77.

9. Bronfenbrenner U. Toward an experimental ecology of human development. Am Psychol 1977;32:513-31.

10. Karanikolos M, Heino P, McKee M, et al. Effects of the Global Financial Crisis on Health in High-Income Oecd Countries: A Narrative Review. Int J Health Serv 2016;46:208-40.

11. Frasquilho D, Gaspar Matos M, Salonna F, et al. Mental health outcomes in times of economic recession: a systematic literature review. BMC Public Health 2016;16:115.
12. Virtanen P, Hammarström A, Janlert U. Children of boom and recession and the scars to the mental health - a comparative study on the long-term effects of youth unemployment. Int $\mathrm{J}$ Equity Health 2016;15:14.

13. Córdoba-Doña JA, Escolar-Pujolar A, San Sebastián M, et al. How are the employed and unemployed affected by the economic crisis in Spain? Educational inequalities, life conditions and mental health in a context of high unemployment. BMC Public Health 2016;16:267.

14. Novo M, Hammarström A, Janlert U. Health hazards of unemployment - only a boom phenomenon? A study of young men and women during times of prosperity and times of recession. Public Health 2000:114:25-9.

15. Hauksdóttir A, McClure C, Jonsson SH, et al. Increased stress among women following an economic collapse - a prospective cohort study. Am J Epidemiol 2013;177:979-88.

16. Bacigalupe A, Esnaola S, Martín U. The impact of the Great Recession on mental health and its inequalities: the case of a Southern European region, 1997-2013. Int J Equity Health 2016;15:17.

17. Moncho J, Pereyra-Zamora P, Tamayo-Fonseca N, et al. Is recession bad for your mental health? The answer could be complex: evidence from the 2008 crisis in Spain. BMC Med Res Methodol 2018;18:78.

18. Novo M, Hammarström A, Janlert U. Do high levels of unemployment influence the health of those non-employed? A gendered comparison of young men and women during boom and recession. Soc Sci Med 2001;53:293-303.

19. Brydsten A, Hammarström A, Strandh M, et al. Youth unemployment and functional somatic symptoms in adulthood: results from the Northern Swedish cohort. Eur J Public Health 2015;25:796-800.

20. Strandh M, Winefield A, Nilsson K, et al. Unemployment and mental health scarring during the life course. Eur J Public Health 2014;24:440-5.

21. Hammarström A, Janlert U. Cohort profile: the northern Swedish cohort. Int J Epidemiol 2012;41:1545-52.

22. American Psychiatric Association. Diagnostic and statistical manual of mental disorders. 5th ed. Arlington: American Psychiatric Publishing; 2013.

23. Hammarström A, Westerlund H, Kirves K, et al. Addressing challenges of validity and internal consistency of mental health measures in a 27-year longitudinal cohort study - the Northern Swedish Cohort study. BMC Med Res Methodol 2016;7;16:4.

24. Novo M, Hammarström A, Janlert U. Does low willingness to respond introduce a bias? Results from a socio-epidemiological study among young men and women. Int $\mathrm{J}$ Soc Welf 1999;8:155-63.

25. Stengård J, Bernhard-Oettel C, Berntson E et al. Stuck in a job: being 'locked-in' or at risk of becoming locked-in at the workplace and well-being over time. Work Stress 2016;30:152-72.

26. Karasek RA, Theorell T. Healthy Work. New York, NY: Basic Books; 1990.

27. Cutler DM, Huang W, Lleras-Muney A. When does education matter? The protective effect of education for cohorts graduating in bad times. Soc Sci Med 2015;127:63-73. 